\title{
INCONSISTENCY AND CORRECTION OF THE GERMAN AMORTIZATION SYSTEM
}

\section{Bruno Luís Hönigmann Cereser ${ }^{*}$ and Aurelio Ribeiro Leite Oliveira}

Received August 03, 2018 / Accepted September 27, 2019

\begin{abstract}
The amortization systems, also called as amortization methods, are used to compute the installment value that a client must disburse (or spend) to pay off a loan or financing with the number of installments and the interest rate agreed for the loan or financing. This paper shows that the German Amortization System makes an inconsistent use of the interest paid in advance in its definition and generates an effective interest rate higher than the contracted, which makes this system abusive and unfair to the clients. In this article, two forms of correcting the German Amortization System are also proposed, making the effective interest rate equals to the contractual interest rate.
\end{abstract}

Keywords: German Amortization System, Equal Installment Loans, Loan and Financing Amortization.

\section{INTRODUCTION}

In many occasions, we resort to loans or financing to buy an expensive consumer good. When we make that financing we need a previous agreement to a payment system (or a payment plan), number of installments and interest rate on this loan/financing. One of the systems to compute the installment value of a financing is the German Amortization System.

On the German Amortization System the installment values are identical, like the French System, also known as Price System. The fundamental difference between these two methods lies in the fact that in the German system the interest of the debt is paid in advance, while in the French method it is to be paid in the current month. Therefore, in the German Amortization System the $k$-th installment contains the $k$-th amortizations and the $k+1$ interest. Due to its definition, on the act of the loan, we need to pay the interest related to the first period.

When we make an anticipated payment of the interest, we need to correct the interest rate or the value of the interest, since this interest is related to the next period. The German Amortization System does not make the proper correction of the interest rate or the interest value and ends up increasing the interest rate of the financing. This fact will be shown in more details on the Sections 4 and 5. Most people do not realize this feature of the German Amortization System.

*Corresponding author - https://orcid.org/0000-0003-0753-9386

IMECC, Unicamp, Campinas - São Paulo, Brazil

E-mails: brunolhcereser@gmail.com, aurelio@ime.unicamp.br 


\section{THE GERMAN AMORTIZATION SYSTEM}

The German Amortization System consists on a payment plan to pay off a debt. This payment system is most commonly used in financing.

On the German Amortization System, the first installment is the only one with a different value. The first installment corresponds only to the interest value over the total value of the financing. The remaining installments have the same value given by the amortization plus the interest refers to the next period.

According to Vendite (2017) and Grigorieva (2016), to describe the German Amortization System, consider an initial debt of $S_{0}$, contracted at interest $j$ and $n$ periods. The interest of the period $k$ is given by Equation 1 .

$$
J_{k}=S_{k} j
$$

Where $S_{k}$ is the remaining debt value in period $k$ and $J_{k}$ is the interest of the period $k$. In other words, $S_{k}$ is the financial value reduced by the amortizations until the period $k$ as shown in Equation 2.

$$
S_{k}=S_{0}-\left(\sum_{i=1}^{k-1} A_{i}\right) .
$$

Where $S_{0}$ is the financial value and $A_{i}$ is the amortization of period $i$. On the financing act the client pays $S_{0} j$, as the anticipated interest. Let $P_{0}=S_{0} j$. Therefore, on the act of financing (period $0)$ the client receives the value Equation 3.

$$
S_{0}(1-j)
$$

Which is the financial value deducted of the anticipated interest.

This amortization system has equal installments for all periods (except by the zero installment $\left.P_{0}\right)$, then $P_{1}=P_{2}=P_{3}=\ldots=P_{k}=\ldots=P_{n}=P$. The installment of the period $k$ is given by Equation 4.

$$
P_{k}=A_{k}+J_{k}
$$

Where $A_{k}$ is the amortization of the period $k$ and $J_{k}$ is the interest in period $k$. In other words, the installment of the period $k$ is the interest plus the amortization. Using Equation 1 on 4 we have the Equation 5.

$$
P_{k}=A_{k}+S_{k} j
$$

As $P_{k}=P_{k+1}$ for $k=1,2, \ldots, n-1$ and using Equation 5 we have the Equation 6 .

$$
A_{k}+S_{k} j=A_{k+1}+S_{k+1} j
$$

Using that $S_{k+1}=S_{k}-A_{k}$, which means that the remaining debt of the period $k+1$ is equal to the remaining debt of period $k$ minus the amortization of the period $k$. Applying this equation on Equation 6 results on Equation 7.

$$
A_{k}+S_{k} j=A_{k+1}+\left(S_{k}-A_{k+1}\right) j .
$$


By isolating the $A_{k}$ on Equation 7 we have the amortization of the installments $k=1,2,3, \ldots, n-1$ given by Equation 8 .

$$
A_{k+1}=\frac{A_{k}}{(1-j)} \quad k=2,3, \ldots, n
$$

The Equation 8 is a recursive relation. That means:

$$
A_{2}=\frac{A_{1}}{(1-j)}, \quad A_{3}=\frac{A_{2}}{(1-j)}, \quad A_{4}=\frac{A_{3}}{(1-j)} \quad \cdots
$$

From them, we obtain:

$$
\begin{gathered}
A_{2}=\frac{A_{1}}{(1-j)}, \quad A_{3}=\frac{A_{2}}{(1-j)}=\frac{A_{1}}{(1-j)^{2}}, \quad A_{4}=\frac{A_{3}}{(1-j)}=\frac{A_{1}}{(1-j)^{3}} \quad \ldots . \\
A_{k}=\frac{A_{1}}{(1-j)^{k}} .
\end{gathered}
$$

Using Equation 9 we have the sum of the amortizations given by Equation 10.

$$
\sum_{k=1}^{n} A_{k}=\sum_{i=1}^{n} \frac{A_{1}}{(1-j)^{i-1}} .
$$

The Equation 10 is a geometric series of common ratio $r=\frac{1}{1-j}$. The sum of all amortizations needs to be equal to the financial value, that give us the geometric series common ratio Equation 11.

$$
\sum_{i=1}^{n} \frac{A_{1}}{(1-j)^{i-1}}=S_{0}
$$

Using that the sum of a finite geometric series of common ratio $r$ is given by $\frac{a_{0}\left(1-r^{n}\right)}{1-r}$, where $a_{0}$ is the value of the first term of the series, we have the value of the amortization of the first installment $A_{1}$ given by the Equation 12 .

$$
A_{1}=\frac{S_{0} j}{(1-j)^{1-n}-(1-j)}
$$

With the value of $A_{1}$, we can compute the value of every amortization using the Equation 8 . The value of $P_{k}$ is identical for every installment, therefore, we need only to calculate $P_{1}=A_{1}+J_{1}$, where by $J_{1}=j\left(S_{0}-A_{1}\right)$. With the installment value, we can compute the interest value using and we have $J_{k}=P-A_{k}$, where $P=P_{1}$ and $A_{k}$ is the value of the amortization of the period $k$.

The value of each installment is identical for every period, with the exception of the period 0 , and includes the anticipated interest value and the amortization. The installment $k$ is given by Equation 13.

$$
P_{k}=A_{k}+j\left(S_{0}-\sum_{i=1}^{k} A_{i}\right) \quad k=2,3, \ldots, n .
$$


Where $j\left(S_{0}-\sum_{i=1}^{k} A_{i}\right)$ corresponds to the anticipated interest paid over the balance debt and $A_{k}$ corresponds to the amortization. As the installments are identical, we just need to compute the value of the installment of period $1\left(P_{1}\right)$ and repeat it $n$ times. The installment of period 1 is given by Equation 14 .

$$
P_{1}=P=A_{1}+j\left(S_{0}-A_{1}\right)
$$

Then every installment is given by Equation 15 .

$$
P_{k}=P_{1}=P \quad k=2,3, \ldots, n .
$$

The Table 1 brings a summary of the German Amortization System. Given $S_{0}$ the financial value, $n$ the number of installments and $j$ the interest rate.

Table 1 - German Amortization System

\begin{tabular}{c|cc}
\hline$A_{0}$ & 0 & \\
\hline$A_{1}$ & \multicolumn{2}{|c}{$S_{0}$} \\
& $(1-j)^{1-n}-(1-j)$ & \\
\hline$A_{k}$ & $\frac{A_{k-1}}{(1-j)}$ & $k=2,3, \ldots, n$ \\
\hline$P_{0}$ & $S_{0} j$ & \\
\hline$P_{k}$ & $A_{1}+j\left(S_{0}-A_{1}\right)$ & $k=1,2,3, \ldots, n$ \\
\hline$J_{k}$ & $P_{k}-A_{k}$ & $k=0,1,2,3, \ldots, n$ \\
\hline
\end{tabular}

Where $A_{k}$ is the value of the amortization value of $k$-th installment, $P_{k}$ is the value of $k$-th installment, $J_{k}$ is the interest value of $k$-th installment where $k=0,1,2, \ldots, n, j$ is the interest rate on the financing, $S_{0}$ is the financial value and $n$ is the number of installments.

\section{INTERNAL RATE OF RETURN}

To show that the German Amortization System generates an interest rate higher than the interest used to perform the computation, a technique used to determine the interest rate of a receipt and payment system, which is often used to analyse investments. This technique is named the Internal Rate of Return (IRR).

The internal rate of return (IRR) is massively employed, some application of this technique is provided in Sandahl \& Sjögren (2003), Magni (2009), Hahn \& Kuhn (2012), Pasqual et al. (2013), among others.

Some articles like Magni (2013) argues that IRR often conflicts with NPV and suffers from many weaknesses, but the examples provided by the author involve some kind of randomness or even speculations like a building market price or a high risk investment. A building market price depends on many factors like localization, offer and demand on the local market, the regional economic growth, speculations and many others uncertain factors (more in Ferraudo et al. (2016)). The IRR is a polynomial solution and presupposes deterministic data and hypotheses. 
In another example the author proposes a high risk investment with monthly gains and losses. The IRR given a $10 \%$ rate and the authors says that means the investment have obtained a monthly rate of $10 \%$. That is an equivocated interpretation of the result. In the context of the investment, that means from the initial month until the final month you have $10 \%$ more than the initial investment. In the same contest the high risk investment at the final point, have earned the same amount of a no risk investment with a $10 \%$ month rate that begins at the same initial and end on the same final month of higher risk investment.

Fortunately, a financing does not have uncertain or variations on the monthly payment like the cases pointed by Magni (2013) and Magni (2015), it is a payment system with equal installments and fixed interest rate (with the exception of the zero installment).

According to Hastings (2015) and Sobrinho \& Bertolo (1997), the internal rate of return (IRR), represented by $j^{*}$ is the value (interest rate) that brings the present and future values of a receipts and payments flow equals to zero. In other words, given $V_{i}, i=0,1, \ldots, n$ the knowing receipt and payments flow, then $j^{*}$ is the value that solves the Equation 16.

$$
V_{0}+\frac{V_{1}}{\left(1+j^{*}\right)}+\frac{V_{2}}{\left(1+j^{*}\right)^{2}}+\ldots+\frac{V_{n}}{\left(1+j^{*}\right)^{n}}=0 .
$$

Note that each $V_{i}(i=0,1, \ldots, n)$ represents a receipt or a payment, therefor is negative (usually for payments) or positive (usually for receipts). The Equation 16 can be represented by a polynomial equation of $n$ degree, as it is shown in Equation 17.

$$
V_{0}+V_{1} x+V_{2} x^{2}+\ldots+V_{n} x^{n}=0 .
$$

Where $x=\frac{1}{1+j^{*}}$.

For $n=\{1, \ldots, 4\}$, the solution of Equation 17 can be easily obtained. When $n \geq 5$ we can find $j^{*}$ with a software to solve polynomial equation or a numerical method to solve polynomial equations. To a receipts and payments flow have a solution, it is necessary, but not sufficient, that the flow has at least one receipt and one payment, mathematically that means the flow has at least one value with a signal change. For loans and financing, the Equation 17 always have a single solution, as it will be shown in Subsection 3.1 and Section 5.

\subsection{A Financing Internal Rate of Return}

To apply the IRR to a financing or a loan made by the German amortization system, on the perspective of the client, he will receive the total of $S_{0}(1-j)$ where the $S_{0}$ is the financial value and $j$ is the interest rate. That value will be received by the client; therefore it is a positive value in his perspective.

Each month he will pay the installment. Therefor it is a negative value in his perspective. Let $P$ be the value of the installment, since it is a negative value on the client perspective, let use $-P$ to represent the payment of an installment. Using the Equation 17 we have the Equation 18 to the IRR of the financing.

$$
S_{0}(1-j)-P x-P x^{2}-\ldots-P x^{n}=0 .
$$


Where $x=\frac{1}{1+j^{*}}$.

\section{MOTIVATION}

Given a financing by the German Amortization System, where

- Financial value: 1000.00 .

- Interest rate: $5.00 \%$ per period.

- Number of periods: 4.

On the financing act, the client needs to pay the interest of $J_{0}=1000 * 0.05=50$ dollars and has no amortization on the period 0. Using Equation 12 we have $A_{1}=231.11$. We use the Equation 8 for every other amortization. The interest of the period 1 is given by $J_{1}=\left(S_{0}-A_{1}\right) j=(1000-$ 231.11) $0.05=38.44$. With $J_{1}$ and $A_{1}$ we can compute $P=P_{1}=J_{1}+A_{1}=269.55$ where $P=P_{1}$ using the fact of this type of financing have equal installments. With the installment value we can compute the interest value as $J_{k}=P-A_{k}$ where $A_{k}$ is the amortization of $k$-th period.

The installments, interest and amortization of each period are displayed in Table 2.

Table 2 - Financing by the German Amortization System

\begin{tabular}{rllll}
\hline Period & Installment & Interest & Amortization & Balance \\
\hline 0 & 50.00 & 50.00 & 0.00 & 1000.00 \\
1 & 269.55 & 38.44 & 231.11 & 768.89 \\
2 & 269.55 & 26.28 & 243.27 & 525.62 \\
3 & 269.55 & 13.48 & 256.07 & 269.55 \\
4 & 269.55 & 0.00 & 269.55 & 0.00 \\
\hline
\end{tabular}

Adjusting the data of the Table 2 to a receipt and payments flows the Table 3 are obtained where a negative sign represents the receipt of the financial value and positive represents every installment.

Table 3 - Receipts and payments of the financing

\begin{tabular}{c}
\hline Receipts/Payments \\
\hline 950.00 \\
-269.55 \\
-269.55 \\
-269.55 \\
-269.55 \\
\hline
\end{tabular}

Using the IRR, a tool that evaluates a rate interest of a receipts and payments flow, an interest rate of $-5.26 \%$ is obtained for the receipts and payments flow of Table 3. Which means, the real interest rate on the financing is $5.26 \%$, significantly $(0.26 \%)$ more than the interest rate accorded. 
When the financing have large amount of money and high interest, such like the quick financing of a building or an urgent loan to a factory, the difference value is very large. For example, take a financing of 10 million for the construction of a large building with an interest rate of $3.5 \%$ per month and 120 installments. That results in a payment of 343,702 per month with GAS. After the final installment, the IRR is $3.63 \%$ per month, which makes the payment 1.3 million more than should be along the payments. The bank probably needs to repay the client in the present value, which is around 21 million at the end of the financing considering the interest of $3.5 \%$ per month.

\section{PROBLEM ANALYSIS AND CORRECTION}

Given a generic financing with:

- Financial value: $S_{0}$.

- Interest rate: $j$ per period.

- Number of periods: $n$.

Table 4 - Generic financing by the German Amortization System

\begin{tabular}{rllll}
\hline Period & Installment & Interest & Amortization & Balance \\
\hline 0 & $j S_{0}$ & $j S_{0}$ & 0 & $S_{0}$ \\
1 & $P$ & $j\left(S_{0}-A_{i}\right)$ & $A_{1}$ & $S_{0}-A_{1}$ \\
2 & $P$ & $j\left(S_{0}-\sum_{i=1}^{2} A_{i}\right)$ & $\frac{A_{1}}{(1-j)}$ & $\left(S_{0}-\sum_{i=1}^{2} A_{i}\right)$ \\
$\cdot$ & $\cdot$ & $\cdot$ & $\cdot$ \\
$\cdot$ &. & $\cdot$ & $\cdot$ & $\cdot$ \\
. &. & $\cdot$ & $\cdot$ & $\cdot$ \\
\hline $\mathrm{n}$ & $P$ & $\cdot$ & $\frac{A_{1}}{(1-j)^{n-1}}$ & 0 \\
\hline
\end{tabular}

To apply the IRR to the financial value and it installments, is equivalent to using the Equation 16 to determine the actual interest rate. Note that the actual given value received for the financing is $S_{0}(1-j)$ an $P_{k}=P_{1}=P$ for all $k=2,3, \ldots, n$. Applying the Equation 16 we have the Equation 19.

$$
S_{0}(1-j)-\frac{P}{\left(1+j^{*}\right)}-\frac{P}{\left(1+j^{*}\right)^{2}}-\ldots-\frac{P}{\left(1+j^{*}\right)^{n}}=0 .
$$

Using $n=1$ to determine $j^{*}$, by Equation 12 we have Equation 20 .

$$
A_{1}=S_{0}
$$

By Equation 14 and Equation 20 we have Equation 21.

$$
P=S_{0}
$$


The IRR of this financing is given by Equation 22.

$$
S_{0}(1-j)-\frac{P}{\left(1+j^{*}\right)}=0 .
$$

By Equation 21 and Equation 22 we have $j^{*}=\frac{j}{1-j}$. Since $j>0$ assuming $j<1$ because if $j>1$ the whole financing value will be paid on the first period. Thus, $0<j<1$ leads to $j^{*}>j$.

Now we will proof that for any number of installments the German amortization system has a real interest of $j^{*}=\frac{j}{1-j}$. When $n=k$ the value of $j^{*}$ is given by Equation 23 .

$$
-S_{0}(1-j)+\sum_{i=1}^{k}\left(\frac{P}{1+j^{*}}\right)=0
$$

Note that the $\operatorname{sum} \sum_{i=1}^{k}\left(\frac{P}{1+j^{*}}\right)$ is a geometric progression of ratio $\frac{1}{1+j^{*}}$. The sum of a geometric progression o ratio $r$ is given by $\sum_{i=x}^{y} r^{i}=r^{x}\left(\frac{1-r^{y-x+1}}{1-r}\right)$, using that result, the Equation 23 can be written as the Equation 24.

$$
-S_{0}(1-j)+P\left(\frac{\left(1+j^{*}\right)^{k}-1}{j^{*}\left(1+j^{*}\right)^{k}}\right)=0
$$

Using the Equations 14 and 12 to replace $P$ of Equation 24 by a function of $S_{0}, j$ and $k$ and simplifying we have Equation 25.

$$
-S_{0}(1-j)+S_{0} j\left(\frac{1}{(1-j)^{k}}\right)\left(\frac{\left(1+j^{*}\right)^{k}-1}{j^{*}\left(1+j^{*}\right)^{k}}\right) .
$$

Using $j^{*}=\frac{j}{1-j}$ on Equation 25 and simplifying we have Equation 26.

$$
-S_{0}(1-j)+S_{0} j\left(\frac{1}{(1-j)^{k}}\right)\left(\frac{(1-j)-(1-j)^{k+1}}{j}\right) .
$$

Simplifying the Equation 26 we obtain Equation 27.

$$
-S_{0}(1-j)+S_{0}\left(\frac{(1-j)-(1-j)^{k+1}}{1-(1-j)^{k}}\right) .
$$

Isolating $S_{0}(1-j)$ on Equation 27 we obtain Equation 28.

$$
S_{0}(1-j)\left(-1+\left(\frac{1-(1-j)^{k}}{1-(1-j)^{k}}\right)\right)=0 .
$$

Therefore, we proof that, for any $k$ installments, the value of installments of a same period of time, in our case the period zero, produces an interest rate higher than $j$. We proof that the 
effective interest rate of the German amortization system is $j^{*}=\frac{j}{1-j}$ and considering that $0<$ $j<1$ we have $j^{*}>j$.

For the German amortization system the interest is paid in advance, therefor it must be adjusted. On Subsections 5.1 and 5.2 we propose two ways to correct the reported inconsistency of the German amortization system, the first makes the fix directly on the interest rate, the second makes the fix on each period, which makes the installment to decline a little over the periods.

\subsection{Correction I}

The goal is to anticipate the financing interest rate and make the needed computations to fix the effective interest rate. Our objective is to have an effective interest rate of $\mathrm{j}$. Let $j_{c}=\frac{j}{j+1}$ be the interest rate that will be used to make the computations. Since it effective interest rate is given by $j^{*}=\frac{j_{c}}{1-j_{c}}$ we have the effective interest rate given by Equation 29 .

$$
j_{c}=\frac{j^{*}}{j^{*}+1}=\frac{\frac{j}{1-j}}{\frac{j}{1-j}+1}=j .
$$

By Equation 29, if we use $j_{c}=\frac{j}{j+1}$ to make the computations we will have an effective rate equals $j$ that corrects the interest rate. The financing used as an example with the fixed interest rate is displayed in Table 5.

- Financial value: 1000.00 .

- Interest rate: $5 \%$.

- Adjusted interest rate: $4.76 \%$ per period $\left(j_{c}=\frac{j}{j+1}\right.$ - will be use on the computations).

- Number of periods: 4.

Table 5 - Financing by the German Amortization System

\begin{tabular}{rllll}
\hline Period & Installment & Interest & Amortization & Balance \\
\hline 0 & 47.62 & 47.62 & 0.00 & 1000.00 \\
1 & 268,58 & 36.57 & 232.01 & 768.89 \\
2 & 268,58 & 24.97 & 243.61 & 525.62 \\
3 & 268,58 & 12.79 & 255.79 & 269.55 \\
4 & 268,58 & 0.00 & 268.58 & 0.00 \\
\hline
\end{tabular}

Adjusting the data of the Table 5 to a receipts and payments flows the Table 6 are obtained where a negative sign represents the receipt of the financial value and positive represents every installment. 
Table 6 - Receipts and payments of the financing

\begin{tabular}{c}
\hline Financing \\
\hline 950.00 \\
-268.58 \\
-268.58 \\
-268.58 \\
-268.58 \\
\hline
\end{tabular}

This receipts and payments flow have an IRR of $-5,00 \%$, compatible with the combined interest rate for the financing.

\subsection{Correction II}

The second possible way to correct the inconsistency of the method is to correct every interest individually, which, in general, is useful on an ongoing financing. To fix the financing by this second way, we multiply every interest by $\frac{1}{j+1}$. The fixed example financing are displayed on Table 7.

- Financial value: 1000.00 .

- Interest rate: $5.00 \%$ (desired).

- Number of periods: 4.

Table 7 - Financing by the German Amortization System

\begin{tabular}{rllll}
\hline Period & Installment & Interest & Amortization & Balance \\
\hline 0 & 47.62 & 47.62 & 0.00 & 1000.00 \\
1 & 267,72 & 36.57 & 232.01 & 768.89 \\
2 & 268,30 & 24.97 & 243.61 & 525.62 \\
3 & 268,91 & 12.79 & 255.79 & 269.55 \\
4 & 269.55 & 0.00 & 268.58 & 0.00 \\
\hline
\end{tabular}

Adjusting the data of the Table 7 to a receipts and payments flows the Table 8 are obtained where a negative sign represents the receipt of the financial value and positive represents every installment. 
Table 8 - Receipts and payments of the financing

\begin{tabular}{c}
\hline Receipts and payments of the financing \\
\hline 952.38 \\
-267.72 \\
-268.30 \\
-268.91 \\
-269.55
\end{tabular}

This receipts and payments flow have an IRR of $-5,00 \%$, compatible with the combined interest rate for the financing.

\section{CONCLUSION}

In this paper, we prove that the German Amortization system has an inconsistency in its definition, and that make it unfair to the clients on financing or loans. By anticipating the interest without adjusting the interest rate, the effective rate of interest is higher than it should be. With the proper adjustments, like the Correction I and Correction II proposed on Subsections 5.1 and 5.2 respectively in this paper, the system becomes fair with an effective interest rate equals to the accorded.

The Correction I is the more indicated because maintain the identical installments characteristic of the German amortization system (the only exception is the installment that must be paid in the period zero). The Correction II makes the installments of the system to slight decrease over the periods, and that kind of correction is recommended for ongoing financing or loans contracted by the German amortization System. Fix the German amortization system is very important, since it brings benefits to the client, reduces the installments values. The Noncompliance rate and the number of lawsuits related to the unfair effective interest rate will be reduced.

\section{References}

[1] Ferraudo GM, LouzAda F \& FERREIRA JF. 2016. Interference of the market value of urban lots from the perspective of survival analysis. Case study: city of São Carlos, São Paulo, Brazil. Pesquisa Operacional, 36(2): 355-374.

[2] Grigorieva E. 2016. Real-Life Applications of Geometric and Arithmetic Sequences. In: Methods of Solving Sequence and Series Problems. pp. 191-225. Springer.

[3] Hahn GJ \& KuHN H. 2012. Value-based performance and risk management in supply chains: A robust optimization approach. International Journal of Production Economics, 139(1): 135-144.

[4] Hastings KJ. 2015. Introduction to Financial Mathematics. CRC Press. 
[5] Magni CA. 2009. Splitting up value: A critical review of residual income theories. European Journal of Operational Research, 198(1): 1-22.

[6] Magni CA. 2013. The internal rate of return approach and the AIRR paradigm: a refutation and a corroboration. The Engineering Economist, 58(2): 73-111.

[7] Magni CA. 2015. Aggregate Return On Investment for investments under uncertainty. International Journal of Production Economics, 165: 29-37.

[8] Pasqual J, Padilla E \& Jadotte E. 2013. Equivalence of different profitability criteria with the net present value. International Journal of Production Economics, 142(1): 205-210.

[9] SAndahl G \& SJÖGREN S. 2003. Capital budgeting methods among Sweden's largest groups of companies. The state of the art and a comparison with earlier studies. International journal of production economics, 84(1): 51-69.

[10] Sobrinho V \& Bertolo. 1997. Matemática financeira. Atlas.

[11] Vendite LL. 2017. Matemática Financeira e a Utilização de Planilhas Eletrônicas. Ciência Moderna. 